Eixo Temático: Formação Profissional do Biólogo

\title{
ET-02-002 \\ O PROGRAMA INSTITUCIONAL DE BOLSA DE INICIAÇÃO DOCÊNCIA - PIBID E SUAS CONTRIBUIÇÕES PARA A FORMAÇÃO DOCENTE EM CURSOS DE LICENCIATURA
}

Maria Rosileide Bezerra de Carvalho, Cristiane Ferreira Mercês, Aline Teles Ferreira, Lys Ayanne Dias Santos, Grasiele Santana Santos

Universidade do Estado da Bahia - UNEB, Bahia.

http://dx.doi.org/10.21472/congrebio2016.et-02-002

\section{RESUMO}

O presente artigo tem por objetivo geral discutir o papel do Programa Institucional de Bolsa de Iniciação à Docência, enquanto política educacional, sobre a formação inicial docente, em um contexto de reestruturação produtiva sob a égide das políticas neoliberais do Estado. Utilizou-se como referencial teórico-metodológico o materialismo histórico-dialético. A modalidade de investigação inscreve-se como um estudo de caso. Os dados foram obtidos mediante consulta a documentos institucionais. A partir de uma breve abordagem sóciohistórica da política educacional brasileira, o Programa foi caracterizado do ponto de vista normativo, em sua formulação na esfera Federal. Em seguida, são descritos os contextos de implementação do PIBID na Universidade do Estado da Bahia e no Curso de Ciências Biológicas do Campus II, Alagoinhas, Bahia, buscando-se a identificação de suas repercussões acadêmico-pedagógicas. Depreende-se que o PIBID pode contribuir efetivamente para o desenvolvimento de uma prática pedagógica pautada na vivência histórica e cultural, promovendo um sinergismo virtuoso de políticas públicas. (CAPES).

Palavras-chave: PIBID; Formação de Professores; Políticas Educacionais.

\section{INTRODUÇÃO}

A proposição e a implementação das políticas educacionais brasileiras, com sua orientação marcadamente neoliberal nas últimas décadas, têm assumido a qualidade da educação básica como estratégica para o aprimoramento do processo de acumulação de riquezas e aprofundamento do capitalismo.

Em torno da segunda metade dos anos 1990, a educação e a formação de professores ganham importância estratégica para a realização das reformas educacionais, particularmente a partir do Governo Fernando Henrique Cardoso. A reforma curricular dos cursos de graduação, advinda da Lei no 9.394/1996 (de Diretrizes e Bases da Educação Nacional - LDB) (BRASIL, 1996), foi deflagrada pela Secretaria de Educação Superior (SESu), do Ministério da Educação (MEC), através do Edital $n^{\circ}$ 04, de 4 de dezembro de 1997, com orientações de que tais Diretrizes Curriculares deveriam possibilitar às IES definir os perfis profissionais para cada área de conhecimento, garantindo uma flexibilidade de cursos e de integração do ensino de graduação com a pós-graduação, e, as competências e habilidades que se deseja desenvolver nos seus estudantes.

A vinculação entre o processo de formação educacional e as exigências do setor produtivo, seja no ensino médio ou superior, fica evidente em documentos e discursos oficiais que visam adequar a formação de profissionais ao atendimento das demandas de um mercado globalizado. Desta forma, a crise educacional passa a ser descrita como uma crise de eficiência e produtividade do sistema, cuja superação dependeria da adoção de mecanismos corretivos 
baseados no mercado. Este aparece, então, como um regulador das políticas educacionais e consequentemente da formação docente, tendo em vista que as regulamentações do Conselho Nacional de Educação, intensificadas no período de 1999 a 2002, colocam no centro do debate a atuação dos professores (VARJÃO, 2008).

Assim, a definição de competências é apresentada como nuclear na organização curricular. Dias (2001) destaca que a proposta de currículo para a formação do professor, pautada em competências, enfatiza as dimensões técnica e administrativa, em detrimento das dimensões ética, moral e política.

Ao analisar a transição na política educacional decorrente da mudança de Governo, de Fernando Henrique Cardoso para Luis Inácio Lula da Silva, Lopes (2004) identifica uma continuidade, entre as políticas curriculares dos dois governos. Tais políticas neoliberais de educação, caracteristicamente compensatórias, focais e assistencialistas resultaram em fracasso. A qualidade da educação básica e superior anunciada pelo Estado a partir da Lei de Diretrizes e Bases da Educação de 1996, não alcançou resultados satisfatórios para a classe trabalhadora, bem como a formação de professores não vem atendendo às demandas nacionais.

Neste cenário de crise educacional, o Governo Federal, através da Coordenação de Aperfeiçoamento de Pessoal de Nível Superior (CAPES), cria o PIBID, que entre outros objetivos, visa a incentivar a formação de docentes em nível superior para a educação básica, a contribuir para a valorização do magistério e a elevar a qualidade da formação inicial de professores nos cursos de licenciatura, promovendo a integração entre educação superior e educação básica.

O PIBID constitui um dos Programas da Diretoria de Educação Básica Presencial (DEB), criada em meados de 2007, quando a Lei no 11.502/2007 (BRASIL, 2007), conferiu à Coordenação de Aperfeiçoamento de Pessoal de Nível Superior (CAPES) as atribuições de induzir e fomentar a formação inicial e continuada de profissionais da educação básica e estimular a valorização do magistério em todos os níveis e modalidades. Esta vinculação institucional advinda na formulação do Programa traduz uma decisão estratégica de fomentar a integração entre programas de pós-graduação, cursos de formação de professores e escolas públicas de Educação Básica.

Neste último aspecto, o PIBID poderá minimizar a separação explícita entre as atividades de ensino e pesquisa na universidade e a valorização da pesquisa em detrimento do ensino (de graduação) no meio acadêmico, que, segundo Diniz-Pereira (2011), trazem prejuízos enormes à formação profissional e, particularmente, à formação de professores.

A institucionalização do PIBID principia com a substituição das Portarias que o regulamentavam, pelo Decreto $n^{0}$ 7.219/2010 (BRASIL, 2010). Em 4 de abril de 2013, a Presidente Dilma Rousseff sanciona a Lei $\mathrm{n}^{\circ}$ 12.796/2013 (BRASIL, 2013) que altera a Lei $n^{\circ}$ 9.394, de 20 de dezembro de 1996, que estabelece as diretrizes e bases da educação nacional, para dispor sobre a formação dos profissionais da educação e dar outras providências, traz no inciso $5^{\circ}$, do art. 62, a normalização do PIBID enquanto política de Estado, objetivando viabilizar sua consolidação e continuidade na agenda das políticas públicas educacionais.

Ao ser lançado, em 2007, a prioridade de atendimento do PIBID eram as áreas da Física, Química, Biologia e Matemática para o ensino médio, dada a carência de professores nessas disciplinas. A partir de 2009, o programa passou a atender toda a Educação Básica, incluindo educação de jovens e adultos, indígenas, campo e quilombolas.

O crescimento do PIBID, no período compreendido entre os Editais, já o coloca, em janeiro de 2011, como o segundo maior programa de bolsas da CAPES, com 31.252 bolsas. Após o Edital de 2012, são totalizadas 49.231 bolsas.

Em 02 de agosto de 2013, a CAPES divulgou o Edital n ${ }^{\circ}$ 61/2013 para seleção de novos Projetos Institucionais. Com este Edital, o PIBID visa à concessão de 72.000 bolsas, sendo que 10.000 serão destinadas a alunos de licenciatura do Programa Universidade para Todos - ProUni e aos professores envolvidos na orientação e supervisão dos mesmos.

O financiamento do PIBID é regulamentado pelo Decreto $n^{0}$ 7.219/2010 (BRASIL, 2010), que estabelece o pagamento das bolsas diretamente aos beneficiários por meio do 
Sistema de Auxílios e Concessões (SAC), da CAPES. Ademais, é repassado um recurso de custeio para as IES. Este recurso baseia-se no número de bolsistas de iniciação à docência participantes do projeto institucional. A base de cálculo para o valor do recurso de custeio é de R\$ 750,00/ano por bolsista de iniciação à docência participante do projeto institucional, até o limite de R\$ 30.000,00 por subprojeto/ano. A execução orçamentária do PIBID - bolsas e custeio - nos exercícios 2009, 2010 e 2011, totalizou R 239.038.820,14.

As inúmeras avaliações positivas realizadas pelos atores do PIBID, e divulgadas em eventos acadêmicos nacionais, endossam a proposição do sinergismo das ações empreendidas entre a Universidade e a Educação Básica no âmbito do Programa. Entretanto, a despeito desses resultados, importa perquirir se a Universidade, a partir da implementação do PIBID, tem redirecionado o ensino no sentido de superar a simples formação de mão de obra especializada em prol de uma educação pelo trabalho cujo objetivo maior seja a emancipação humana.

\section{1- O CURSO DE LICENCIATURA EM CIÊNCIAS BIOLÓGICAS UNIVERSIDADE DO ESTADO DA BAHIA - UNEB, CAMPUS II: O CENÁRIO}

DA

A Universidade do Estado da Bahia é estruturada no sistema multicampi, possui atualmente 29 departamentos instalados em 24 Campi, sendo um na Capital do Estado, Salvador, e os demais em municípios do interior do Estado, desempenhando papel destacado na interiorização do Ensino Superior. O Campus II está localizado em Alagoinhas, Município sede do Território de Identidade Litoral Norte e Agreste Baiano, de coordenadas geográficas $12^{\circ} 08^{\prime}$ de latitude sul e $38^{\circ} 30^{\prime}$ de longitude oeste.

A autorização de funcionamento da UNEB foi dada pelo Decreto $n^{\circ}$ 92.937/1986 (BRASIL, 1986), e seu recredenciamento aprovado por meio do Ato $\mathrm{n}^{\mathrm{o}} 423 / 2011$, do Conselho Estadual de Educação, em 16/12/2011, por um prazo de oito anos.

Em 2004, o Conselho Universitário da UNEB (CONSU), por meio da Resolução no 267, autorizou o redimensionamento curricular dos cursos de formação de professores da universidade, dentre estes, o Curso de Licenciatura em Ciências Biológicas do Campus II, Alagoinhas, que a partir de então, apresenta carga horária de 3.355 horas, com período mínimo de quatro anos e máximo de seis anos para integralização curricular, sendo a matrícula semestral e a oferta no turno matutino. Até 2011, eram destinadas 70 vagas anuais para o curso, sendo 35 vagas a cada semestre, preenchidas através de processo seletivo realizado pela Comissão Permanente de Vestibular (COPEVE), da UNEB. Deste total, 40\% das vagas são destinados a afrodescendentes e 5\% para candidatos indígenas, conforme Resolução CONSU nº 468/2007. A partir de 2011, foram disponibilizadas 15 vagas, do total ofertado, para serem preenchidas por alunos classificados pelo Sistema MEC/SISU. A partir do vestibular de 2012, foi estabelecida uma entrada anual para o curso, via vestibular, disponibilizando-se um total de 40 vagas. As reservas anteriormente discriminadas foram mantidas, alterando-se apenas o percentual para indígenas, que foi suprimido. Assim, caso exista candidato à vaga, esta será criada adicionalmente.

A procura pelo Curso de Licenciatura em Ciências Biológicas, através de processo seletivo vestibular é a mais representativa, seguida pelas transferências internas. Esta procura tem decrescido ao longo dos anos, o que pode ser explicado pela oferta expressiva de outros cursos por parte de Instituições Privadas de Educação Superior, no Município de Alagoinhas, notadamente no período noturno, e, pela oferta de cursos de graduação de regime especial, como os programas Rede UNEB, PROESP e Plataforma Freire (CARVALHO et al., 2012). Tal decréscimo justifica, em parte, a redução das vagas oferecidas. Ademais, a evasão tem sido bastante expressiva, notadamente no primeiro ano. Achado este, corroborado por Diniz-Pereira (2011), que aponta a dificuldade dos alunos manterem o seu sustento durante a graduação, a baixa expectativa de renda em relação à futura profissão e o declínio do status social da docência como causas para as altíssimas taxas de evasão nos cursos de licenciatura, tanto em instituições públicas como privadas. 
O projeto pedagógico de formação profissional da licenciatura em questão segue as diretrizes curriculares instituídas pelas Resoluções CNE/CP n ${ }^{0}$ 1/2002 (BRASIL, 2002a) e CNE $n^{0}$ 2/2002 (BRASIL, 2002b), ao estabelecer que as habilidades e competências específicas sejam desenvolvidas numa perspectiva multi e interdisciplinar a partir de três eixos: epistemologia e racionalidade, biodiversidade num contexto ecológico e evolutivo e contexto pedagógico, que se articulam. Ademais, são incorporadas 400 horas de prática como componente curricular, 400 horas de estágio curricular e 200 horas de atividades acadêmico-científicas e culturais (AACC).

A UNEB participou dos editais PIBID/CAPES de 2009, 2010 e 2011, que totalizaram, em 2012, a aprovação e implementação de 39 subprojetos em 20 municípios do Estado. A estrutura organizacional é composta por dois coordenadores institucionais, dois de gestão, 39 de área; 79 bolsistas de supervisão e 669 de iniciação à docência. A partir dos Editais PIBID lançados em 2013, houve um aumento significativo de bolsistas: PIBID/CAPES (Edital $n^{\circ}$ 61/2013): 1563 de iniciação à docência e 234 supervisores; PIBID/DIVERSIDADE/CAPES (Edital no 66/2013): 138 de iniciação à docência e 19 supervisores; PIBID/FAPESB (Edital no 18/2013): 100 de iniciação à docência e 10 supervisores.

\section{2- O PIBID/UNEB - CIÊNCIAS BIOLÓGICAS/CAMPUS II: A PROPOSIÇÃO, OS OBJETIVOS E A IMPLEMENTAÇÃO DO SUBPROJETO “ENSINO E PESQUISA: ARTICULAÇÃO POSSÍVEL”}

Em agosto de 2012, iniciaram-se as ações previstas no subprojeto em tela, que possui como eixo a articulação ensino-pesquisa e sua utilização como estratégia de aprendizagem da docência na área de biologia/ciências. Sua proposição emanou da constatação dos elevados índices de evasão e retenção observados no Curso, além da rejeição à docência por parte da maioria dos licenciandos. Para Diniz-Pereira (2011, p. 46-47), "Até mesmo entre os que se candidatam a uma bolsa de "iniciação à docência" na universidade - pleiteando uma primeira experiência na regência de classe - encontraremos estudantes que põem em dúvida a opção pelo magistério, devido fundamentalmente à desvalorização social, salarial e, digamos, acadêmica da profissão".

Ademais, iniciativas que valorizam e qualificam a docência, e contribuam financeiramente para a permanência discente na Universidade, modificam positivamente esta realidade. Nesta perspectiva, o Programa Institucional de Bolsa de Iniciação à Docência (PIBID) constitui estratégia singular para a consecução da integralização curricular discente (CARVALHO, 2012).

Adotou-se como pressuposto a premissa de que a inserção precoce na realidade escolar proporciona ampliação da dimensão prática na formação destes futuros profissionais, potencializando ações transformadoras na sociedade. Pensar um currículo e o fazer universitário que superem a simples formação profissional passa necessariamente pela adoção de uma educação contextualizada, na qual os aspectos sócio-históricos (ético-político, epistemológico e econômico) constituam os pilares dos projetos políticos-pedagógicos, tomando-se o trabalho como princípio educativo, cujo objetivo precípuo é a emancipação humana (MORADILLO, 2010; TONET, 2007; MÉSZAROS, 2005).

Foram definidos no subprojeto os seguintes objetivos: reduzir os índices de evasão do Curso de Licenciatura em Ciências Biológicas UNEB/Campus II; estimular a formação da identidade docente nos bolsistas de iniciação à docência; possibilitar a publicação e divulgação de produções científicas mediante a articulação ensino-pesquisa e teoria-prática.

Selecionou-se como bolsistas de iniciação à docência, 20 discentes regularmente matriculados entre o primeiro e quarto semestre no Curso em questão. Considerou-se, entre outros, o critério de vulnerabilidade socioeconômica no processo seletivo, que incluiu carta de intenções, histórico escolar, currículo e entrevista. Foram previstos desligamento por desinteresse ou inadequada participação no decorrer da implementação do subprojeto, além de substituições anuais visando a ampliar a participação discente. Os bolsistas supervisores, dois professores que atuam em Educação Básica e com formação superior na mesma área de 
conhecimento do subprojeto, foram indicados por seus pares. A coordenação de área foi assumida pela proponente do subprojeto e autora do presente relato.

O critério estabelecido localmente, limitando a participação no processo seletivo aos discentes matriculados nos quatro primeiros semestres, intencionou, especificamente a redução da evasão, visto que, no ensino superior, a taxa de evasão no primeiro ano é duas ou três vezes maior do que a dos anos seguintes (SILVA FILHO et al., 2007).

Foram selecionadas duas escolas estaduais situadas em área central da cidade, uma atendendo 454 alunos, matriculados em classes do $6^{\circ}$ ao $9^{\circ}$ ano, e outra, com 1278 alunos em classes de ensino médio. Os bolsistas de iniciação foram distribuídos equitativamente entre as duas instituições e ao final do primeiro ano letivo realizamos rodízio com os grupos, oportunizando atuação nos dois níveis de ensino supracitados.

Quanto às ações empreendidas, preliminarmente, realizou-se levantamento diagnóstico dos aspectos socioeconômicos, hábitos de estudo dos alunos e condições estruturais e funcionais da oferta dos cursos nas duas escolas, mediante aplicação de questionário semiestruturado, pesquisa documental e observação participante. Os dados obtidos nortearam a execução de ações/intervenções, das quais destacamos: participações e observações nas atividades docentes presentes no cotidiano da escola, tais como: semana pedagógica, planejamentos, reunião de pais e mestres, período de avaliação, conselho de classe; formação de grupos de estudo voltados para o reforço e o estímulo à compreensão de conceitos e temas básicos da Biologia/Ciências, que funcionam em turno oposto ao da oferta do curso nas escolas parceiras; execução de projetos de ensino; realização de aulas de campo e práticas em laboratório que permitam melhor compreensão dos temas abordados; produção de material didático alternativo para o ensino de Biologia e Ciências. Estimulou-se uma coleta sistemática de dados mediante registros no diário de campo, gravações de áudio, vídeo e fotografias visando à produção de resumos e artigos sobre a experiência de formação vivenciada, bem como acerca do ensino na área de conhecimento em questão para a divulgação em eventos acadêmicos.

Paralelamente à atuação nas escolas, eram realizadas reuniões semanais de estudo e planejamento com todos os bolsistas, nas quais socializávamos as experiências de cunho pedagógico e pessoais vivenciadas nas escolas, que muitas vezes redirecionaram nossas intervenções; planejávamos as ações a serem empreendidas; e, nos apropriávamos do referencial teórico que respaldaram as ações e a produção científica resultante.

A implementação do subprojeto Interdisciplinar "Ensino e Pesquisa: Articulação Possível”, selecionado no Edital CAPES/DEB n ${ }^{\circ}$ 61/2013, iniciou as atividades em agosto de 2014. Esta nova proposta apresenta avanços em virtude de seu caráter interdisciplinar, envolvendo as licenciaturas de Matemática e Biologia e pela ampliação de participantes, totalizando 50 bolsas de iniciação à docência, cinco de supervisão e três de coordenação de área, que atuarão em três escolas estaduais de Educação Básica.

Verificamos sinais encorajadores resultantes deste percurso. Observa-se o crescente reconhecimento da identidade docente em muitos bolsistas de iniciação à docência, que têm assumido a opção consciente pelo exercício futuro da profissão de professor. Acreditamos que a articulação teoria-prática e a inserção precoce na realidade escolar conferidas pelo PIBID foram determinantes neste posicionamento. Diniz-Pereira (2011) aponta a influência positiva da participação em experiências educacionais diferenciadas ainda durante a formação acadêmicoprofissional, para a construção de elementos de identidade docente, “[...] em função de uma maior respeitabilidade que passam a conferir ao trabalho docente ao vivenciar a complexidade dos desafios do fazer pedagógico e da descoberta do prazer proporcionado pelas relações pessoais que a dinâmica de sala de aula oportuniza” (DINIZ-PEREIRA, 2011, p. 47-48).

Desenvolve-se pouco a pouco um empoderamento por parte destes bolsistas de iniciação à docência, enquanto atores políticos e sociais, com relação à retomada do espaço representado pelas licenciaturas, ora impregnado pelo "bacharelismo", e o reconhecimento do seu papel na transformação da sociedade através de uma educação que qualifique para a vida e promova a emancipação humana. 
Relativo às intervenções nas escolas, observamos um grau variado de interesse e aprendizagem por parte dos alunos da Educação Básica, motivando a busca e adoção de estratégias pedagógicas diversas visando uma maior participação dos mesmos.

Quanto às dificuldades e limitações identificadas para a implementação do subprojeto, ressaltamos: a falta de autonomia na sua execução orçamentária, ora realizada pela Coordenação Institucional, impondo restrições e cortes que por vezes inviabilizaram a consecução de ações propostas; não comprometimento de alguns bolsistas de iniciação à docência, que no decorrer de suas atuações demonstram pouca afinidade com a docência, buscando permanecer no subprojeto em virtude da bolsa recebida mensalmente. Observou-se maior empenho por parte dos discentes nos dois semestres iniciais, confirmando que o lugar do PIBID nos cursos de licenciatura deve ser prioritariamente no primeiro ano letivo; e, a não disponibilidade de carga horária dos bolsistas supervisores para as atividades propostas fora do espaço escolar.

\section{CONSIDERAÇÕES FINAIS}

O presente artigo ao abordar aspectos normativos, processuais e de resultado na avaliação do PIBID em sua implementação local, suscita o acompanhamento sistemático das ações do Programa e da trajetória acadêmica e profissional dos seus beneficiários, contribuindo para o fortalecimento da articulação ensino-pesquisa no Curso em tela. O PIBID, ao promover o contato com a realidade escolar, a sistematização e realização de planejamento pedagógico, a elaboração e execução de projetos, contribui para a formação docente dos bolsistas participantes. Destacamos, também, a importância da apropriação do referencial teórico que forneceu o embasamento necessário para a articulação factível entre teoria-prática e ensinopesquisa, bem como, o concomitante estímulo à produção científica.

A inserção precoce no cotidiano escolar proporciona ampliação da dimensão prática na formação de licenciandos, potencializando ações transformadoras na sociedade. Assim, o PIBID pode contribuir efetivamente para o desenvolvimento de uma prática pedagógica pautada na vivência histórica e cultural, promovendo um sinergismo virtuoso de políticas públicas.

Pensar um currículo e o fazer universitário que superem a simples formação profissional passa necessariamente pela adoção de uma educação contextualizada, na qual os aspectos sóciohistóricos constituam os pilares dos projetos politico-pedagógicos, o trabalho represente princípio educativo, e cujo objetivo precípuo é a emancipação humana. Nesta perspectiva, apontamos a pertinência da articulação das ações previstas nos subprojetos PIBID com os projetos político-pedagógico das respectivas licenciaturas.

\section{REFERÊNCIAS}

BRASIL. Lei n ${ }^{\circ}$ 9.394, de 20 de dezembro de 1996. Estabelece as diretrizes e bases da educação nacional. Disponível em: <http://www.planalto.gov.br/ ccivil_03/leis/L9394.htm>. Acesso em: 23 mar. 2016.

BRASIL. Lei $n^{0}$ 11.502, de 11 de julho de 2007. Modifica as competências e a estrutura organizacional da fundação Coordenação de Aperfeiçoamento de Pessoal de Nível Superior CAPES, de que trata a Lei $n^{\circ} 8.405$, de 9 de janeiro de 1992; e altera as Leis $\mathrm{n}^{\text {os }} 8.405$, de 9 de janeiro de 1992, e 11.273, de 6 de fevereiro de 2006, que autoriza a concessão de bolsas de estudo e de pesquisa a participantes de programas de formação inicial e continuada de professores para a educação básica. Disponível em: <http://www.planalto.gov.br/ccivil_03/_ato2007-2010/2007/Lei/L11502.htm>. Acesso em: 23 mar. 2016. 
BRASIL. Lei $n^{0}$ 12.796, de 4 de abril de 2013. Altera a Lei $n^{0}$ 9.394, de 20 de dezembro de 1996, que estabelece as diretrizes e bases da educação nacional, para dispor sobre a formação dos profissionais da educação e dar outras providências. Disponível em: <http://www.planalto.gov.br/ccivil_03/_ato2011-2014/2013/lei/l12796.htm>. Acesso em: 23 mar. 2016.

BRASIL. Decreto $\mathrm{n}^{0}$ 92.937, de 17 de julho de 1986. Autoriza o funcionamento da Universidade do Estado da Bahia. Disponível em: $<$ http://www2.camara.leg.br/legin/fed/decret/1980-1987/decreto-92937-17-julho-1986-442927publicacaooriginal-1-pe.html>. Acesso em: 23 mar. 2016.

BRASIL. Decreto no 7.219, de 24 de junho de 2010. Dispõe sobre o Programa Institucional de Bolsa de Iniciação à Docência - PIBID e dá outras providências. Disponível em: $<$ http://www.planalto.gov.br/ccivil_03/_ato2007-2010/2010/decreto/d7219.htm>. Acesso em: 23 mar. 2016.

BRASIL. Portaria CAPES n ${ }^{\circ}$ 38, de 12 de dezembro de 2007. Dispõe sobre o Programa de Bolsa Institucional de Iniciação à Docência - PIBID. Disponível em: $<$ https://www.capes.gov.br/images/stories/download/legislacao/Portaria_Normativa_38_PIBID. pdf>. Acesso em: 23 mar. 2016.

BRASIL. Resolução CNE/CP n ${ }^{\circ}$ 1, de 18 de fevereiro de 2002. Institui Diretrizes Curriculares Nacionais para a Formação de Professores da Educação Básica, em nível superior, curso de licenciatura, de graduação plena. Disponível em: $<$ http://portal.mec.gov.br/cne/arquivos/pdf/rcp01_02.pdf>. Acesso em: 23 mar. 2016.

BRASIL. Resolução CNE/CP n ${ }^{\circ}$ 2, de 19 de fevereiro de 2002. Institui a duração e a carga horária dos cursos de licenciatura, de graduação plena, de formação de professores da Educação Básica em nível superior. Disponível em: <http://portal.mec.gov.br/cne/arquivos/pdf/CP022002.pdf>. Acesso em: 23 mar. 2016.

CARVALHO, M. R. B.; REGO, E. J. L.; QUEIRES, L. C. S. O processo de implantação e funcionamento do Curso de Licenciatura em Ciências Biológicas da Universidade do Estado da Bahia - Campus II - Alagoinhas. Revista Metáfora Educacional, n. 12, p. 3-18, 2012. Disponível em: <http://www.valdeci.bio.br/pdf/n12_2012/carvalho_rego_queires_ o_processo.pdf $>$. Acesso em: 20 jul. 2012.

DINIZ-PEREIRA, J. E. O ovo ou a galinha: a crise da profissão docente e a aparente falta de perspectiva para a educação brasileira. Revista Brasileira de Estudos Pedagógicos, v. 92, n. 230, p. 34-51, 2011. Disponível em: <http://rbep.inep.gov.br/ index.php/rbep/article/download/541/524>. Acesso em: 20 jul. 2012.

LOPES, A. C. Políticas curriculares: continuidade ou mudança de rumos? Revista Brasileira de Educação, n. 26, p. 109-118, 2004. http://dx.doi.org/10.1590/S1413-24782004000200009

MÉSZÁROS, I. A educação para além do capital. São Paulo: Boitempo, 2005.

MORADILLO, E. F. A dimensão prática na licenciatura em química da UFBA: possibilidades para além da formação empírico-analítica. Salvador: Instituto de Física, Universidade Federal da Bahia, 2010. (Tese de Doutorado). 
SILVA FILHO, R. L. L.; MOTEJUNAS, P. R.; HIPÓLITO, O.; LOBO, M. B. C. M. Evasão no ensino superior brasileiro. Cadernos de Pesquisa, v. 37, n. 132, p. 641-659, 2007. http://dx.doi.org/10.1590/S0100-15742007000300007

TONET, I. Educação contra o capital. Maceió: EDUFAL, 2007. 